Geografia e Ordenamento do Território, Revista Electrónica

Centro de Estudos de Geografia e Ordenamento do Território

http://cegot.org

ISSN : 2182-1267

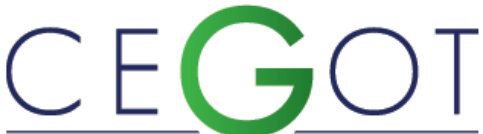

Centro de Estudos de Geografia e Ordenamento do Território
SILVA, ANDRÉ DA

Instituto Benjamin Constant

Av. Pasteur, 368, Urca, Rio de Janeiro, RJ, Brasil. CEP:

222290-240

andrelubs@hotmail.com

\title{
Mobilidade urbana e equidade social: possibilidades a partir das recentes políticas de transporte público na Metrópole do Rio de Janeiro
}

Urban mobility and social equity: possibilities from the recent public transport policies in the Metropolis of Rio de Janeiro

Referência: Silva, André da (2016). Mobilidade urbana e equidade social: possibilidades a partir das recentes políticas de transporte público na Metrópole do Rio de Janeiro. Revista de Geografia e Ordenamento do Território (GOT), n.o 10 (dezembro). Centro de Estudos de Geografia e Ordenamento do Território, p. 293-317, dx.doi.org/10.17127/got/2016.10.014

\section{RESUMO}

Mobilidade é um tema que vem sendo repensado e discutido com mais frequência nos debates urbanos atuais, sendo abordado como algo para além da simples referência à locomoção. No Brasil essa temática tem estado cada vez mais presente no debate sobre o futuro do país e, principalmente, de suas metrópoles, notadamente em razão de seus efeitos no ambiente urbano, não mais apenas como uma técnica da engenharia, mas também por sua função social. O princípio de equidade faz-se então como peça-chave nessa discussão, sendo compreendido como um importante fator atual de ponderamento da eficácia de políticas urbanas, obrigando a repensar estratégias e ações para uma cidade mais sustentável, fazendo-nos questionar o que pode ser feito hoje para termos uma cidade melhor no futuro. Como caso empírico aborda-se as recentes políticas de mobilidade e transporte público no Rio de Janeiro, sede das olímpíadas de 2016.

Palavras-chave: equidade; mobilidade; transportes; planejamento. 


\begin{abstract}
Mobility is an issue that has been rethought and discussed with more frequently in existing urban debates, being addressed as something beyond the mere reference to locomotion. In Brazil, this theme has been increasingly present in the debate on the future of the country and especially its cities, notably because of its effects on the urban environment, not only as an engineering technique, but also for its social function. The principle of equity then it is like a key in this discussion, being understood as an important current factor Weighting of the effectiveness of urban policy, forcing to rethink strategies and actions for a more sustainable city, making us question what can be done today to have a better city in the future. As empirical case approach is the recent policy of mobility and public transport in Rio de Janeiro, host of the 2016 Olympics.
\end{abstract}

Keywords: equity; mobility; transport; planning.

\title{
1. Introdução - Equidade e política urbana
}

Falar hoje em cidade igualitária é considerado por muitos como sem fundamento e perda de tempo, considerando que a produção do espaço urbano capitalista, e até mesmo socialista ou comunista, como alguns assim se intitulam, ainda que suas práticas pouco ou nada tenham a ver com esses regimes, tem como cerne a busca por lucro, com concepções de cidades mais individualistas que sociais. Isto pode ser verdade até um certo ponto, pois todo o avanço técnico atual permitiu que o capitalismo atingisse as menores escalas possíveis do espaço, indo instantaneamente de um continente até um bairro, vila ou tribo, o que inegavelmente pode ter trazido melhorias na vida das pessoas. Ao mesmo tempo isso exigiu a criação e/ou reformulação de ideias, valores, conceitos normas e leis, voltadas em sua maioria para viabilizarem de forma mais eficiente esse alcance capitalista em micro escala.

Na esfera do planejamento urbano, essa ação mais pontual e micro do capitalismo, dirigida em sua maior parte por uma lógica empresarial, não trouxe um melhor quadro de igualdade, sobretudo em cidades latino-americanas, onde o uso do solo urbano é marcado por contrastes entre áreas bem providas de infraestrutura e de equipamentos urbanos,

próximas e mesmo contíguas de outras onde esses recursos são insuficientes e/ou inexistentes. Essa estrutura tem potencializado um debate, que ainda sem pretender alcançar um quadro de igualdade plena, almeje pelo menos uma situação de melhor 
equidade na distribuição de alguns equipamentos e serviços urbanos, na direção de uma justiça distributiva na cidade, reconhecendo peculiaridades e necessidades diversas.

A etimologia da palavra "equidade", segundo Grave (s.d.), vem do latim, e sua definição pode ser entendida como a forma de conceber igualdade tratando de forma desigual e justa os grupos que estão em desvantagem a outro(s), a fim de amenizar algumas desigualdades.

Davey e Devas (1996) afirmam que a promoção de eqüidade social é o princípio pelo qual o governo deveria prover acesso justo e igual para a superação das necessidades sociais básicas, como acesso ao emprego e condições de vida razoáveis, indiferente de renda ou localização. Por este princípio, desigualdades, e mais importante, inequidades ${ }^{1}$, nascem quando preferências são dadas para grupos sociais específicos, graças a circunstâncias tais como diferenças de localização, cor de pele, religião, ou diferenças sociais tais como renda, ou status e poder (CAMPBELL, 1988).

Lima (2004) entende que equidade deveria ser um conceito primário na distribuição de benefícios de urbanização para todos membros de uma sociedade, indiferente de onde eles vivem, onde as condições locacionais, tais como existência de infra-estrutura e acessibilidade associadas a cada localização, deveriam ser tais que tragam restrições a escolhas individuais.

Fireman (2014) defende que equidade e inequidade são conceitos políticos, que além de expressarem quantidades, como os termos igualdade e desigualdade, expressam também uma avaliação moral relacionada à justiça social ${ }^{2}$. Essa perspectiva faz pensar o quanto importante pode ser a presença da ideia de equidade nas políticas urbanas para a produção de cidades melhores para se viver.

\footnotetext{
${ }^{1}$ A palavra inequidade é aqui usada num sentido contrário ao de equidade, buscando designar diferenças oriundas da inexistência desta.

${ }^{2} \mathrm{O}$ conceito de justiça social, discutido desde meados do século XIX, diz respeito à necessidade de alcançar uma repartição equitativa dos bens sociais. Está fundamentado em certos preceitos morais e políticos que cuidam de questões como igualdade de direitos, garantia de direitos básicos e, ainda, solidariedade coletiva. De várias maneiras, a noção de justiça social deriva da luta pela melhoria das condições sociais daqueles que vivem em situação mais desfavorecida. As maneiras como esse objetivo pode ser alcançado variam de acordo com os meios propostos, o que, por sua vez, está relacionado com o contexto ideológico daqueles que adotam a visão. Em termos de desenvolvimento urbano, a justiça social é vista muitas vezes como o cruzamento entre o pilar econômico e o pilar social.
} 
No Brasil a presença da ideia de equidade nas discussões urbanas vem desde a década de 1970 (KOWARIK, 1970; ABREU, 1978; VETTER e MASSENA, 1982), mas só no fim da década de 1980, após o término da ditadura militar, é que ela ganha destaque em documentos oficiais, com a Constituição Federal de 1988, buscando reafirmar os direitos humanos e os objetivos sociais em políticas implementadas a partir de então (LIMA, op. cit.).

Neste ínterim, embora reconhecendo a existência e importância de outros fatores ligados à ideia de eqüidade social, tais como habitação, saneamento, renda, educação, saúde, cultura, dentre outros, existem alguns que, por seu grande poder catalisador de ações, vêm ganhando muita relevância, como a mobilidade, capaz de desencadear inúmeros outros processos na relação com a cidade.

A mobilidade urbana tem estado cada vez mais presente no debate sobre o futuro do Brasil e, principalmente, de suas metrópoles, notadamente em razão de seus efeitos no ambiente urbano, não mais apenas como uma técnica da engenharia, mas também por sua função social. Os debates sobre o direito à cidade, entendido como o usufruto eqüitativo das cidades e seus equipamentos e serviços, dentro dos princípios da sustentabilidade e da justiça social, não estão mais desvinculados do conceito de mobilidade urbana, pelo contrário, este está cada vez mais contido naquele, enquanto uma condição inarredável de participação no mundo urbano (ITDP, 2016). Para além do movimento físico, a mobilidade urbana torna-se também uma ferramenta de justiça social, uma vez que a distribuição espacial dos serviços, equipamentos e atividades urbanas normalmente distam dos locais de moradia da maioria da população - fato que se agrava para as parcelas de menor renda.

Desta forma é que as políticas públicas de mobilidade urbana e transportes coletivos vêm se orientando cada vez mais pela ideia de equidade, levando assim a um repensar da própria ideia de mobilidade, e por conseguinte, da ideia mesmo de transporte. 


\section{Mobilidade urbana: de conceito ligado ao deslocamento físico aos atributos de equidade, cidadania, e bem-estar}

Para além da simples referência à locomoção, a mobilidade é um tema que vem sendo repensado e discutido com mais frequência nos debates urbanos atuais. Segundo Grave (op cit.), apesar da necessidade de leis e normas de conduta para uma convivência coletiva saudável, as ações e projetos voltados para a mobilidade urbana por muitos anos se restringiram à resolutividade dos problemas de trânsito de veículos, não necessariamente nas demandas das pessoas. Ou seja, para a autora, foram fundamentados sobre pilares de uma lógica em que o espaço urbano é majoritariamente destinado aos veículos, sobretudo os individuais. Ações desse tipo que não favorecem o transporte público e uma política de uso do solo que não leve em conta a mobilidade urbana, contribuem para o aparecimento de um número cada vez maior de veículos particulares nas ruas, agravando os congestionamentos e gerando uma pressão política por maior capacidade de tráfego das avenidas, túneis e viadutos. Mesmo quando são realizados representativos investimentos em infra-estrutura para melhorar o fluxo de veículos, os benefícios rapidamente desaparecem, em decorrência da ampliação do espaço viário tornar-se um estímulo a maior utilização do transporte individual.

Os debates atualmente avançam na necessidade de superar alguns limites setoriais, pensando um conceito de mobilidade que oriente as ações necessárias para a implementação de uma política que permita aos cidadãos o direito de acesso mais equitativo e eficiente aos espaços e equipamentos urbanos, e que devolva às cidades o atributo de sustentabilidade socioeconômica e ambiental que muitas perderam.

Muitas abordagens tratam equivocadamente a mobilidade como mero sinônimo de acessibilidade, mas embora ambos façam parte de uma mesma discussão sobre o deslocamento, referem-se a objetos distintos. Kleiman (2011) apresenta a ideia de acessibilidade como sendo a capacidade que um lugar tem de ser alcançado a partir de outros lugares com diferentes localizações geográficas e configurações sociais. Em outras palavras, a acessibilidade seria a qualidade de deslocar-se de um ponto ou de uma área sem ou com redução de barreiras na comunicação dos componentes de um sistema espacial (CASTIELLO; SCIPPACEROLA, 1998, apud KLEIMAN, op cit.). Vasconcellos (2001) defende que 
a acessibilidade remete aos instrumentos físicos que possibilitam a efetivação de deslocamentos, garantindo que os lugares dentro do espaço urbano se tornem acessíveis, e que as pessoas, por sua vez, tenham mobilidade, decorrendo daí a importância de entendermos também a definição desse último conceito.

Vasconcellos (op cit) considera mobilidade com a habilidade humana de movimentar-se em decorrência de condições físicas, culturais e econômicas individuais, e se referem às pessoas e não aos lugares. O autor afirma que durante muito tempo a engenharia de transportes teve uma percepção incompleta do conceito de mobilidade, pois se fundamentava basicamente em instrumentos matemáticos e estatísticos de pouca flexibilidade. Kleiman (op cit.) nos esclarece que embora os dois termos guardem estreitas relações, o conceito de mobilidade não se refere apenas a possibilidade de deslocamento no espaço físico, mas também, e principalmente, a uma capacidade de deslocar-se no espaço social, implicando em interações sociais que viabilizam movimentar-se em âmbitos sociais diferentes. Para Kleiman a mobilidade é uma combinação entre os meios pessoais dados pela sua posição social e os sistemas de circulação e modais de transporte a sua disposição no lugar e contexto de suas vidas.

\begin{abstract}
Neste sentido, a capacidade de mobilidade é uma condição de participação no mundo urbano, mas que para efetivar-se precisa de um conjunto de fatores, como, entre outros, o nível de renda, a existência de modais de transporte coletivos e particulares e sua acessibilidade segundo o nível de renda, de modo que podem existir deslocamentos sem mobilidade. A mobilidade pode, então, ser atribuída como um recurso social importante e integrante da sociedade, isto é, diretamente relacionado ao deslocamento de pessoas entre as diferentes hierarquias sócioespaciais. (KLEIMAN, op cit., p. 3 e 5).
\end{abstract}

Concomitante a esse repensar do conceito de mobilidade, várias propostas emergem a partir das duas últimas décadas na tentativa de relativizar um pouco o tratamento da questão urbana, flexibilizando as análises sobre a cidade, incluindo a defesa da gestão participativa e equidade social, aumentado-se a ênfase nos fatores acessibilidade e mobilidade urbana. A mobilidade gerada pelo transporte, em especial o transporte coletivo, passa a ser compreendida como um instrumento que deve favorecer a plena realização das 
funções sociais da cidade ${ }^{3}$, com a adaptação dos espaços urbanos para essas funções (redes, fluxos e leis).

Alguns pensamentos sobre a cidade buscam reforçar a ideia de uma organização do espaço urbano voltada para produzir áreas mais compactas, equilibradas e eficientes, incentivando a superposição dos usos do solos como forma de reduzir percursos. A mobilidade passa a ser reconhecida nesse contexto como o elemento primeiro na organização do espaço urbano, com os equipamentos de transportes coletivos possibilitando a retroalimentação de diversas atividades.

A mobilidade tende a ser pensada, assim, não apenas no que se refere à ocupação do solo e ao deslocamento, mas também, e sobretudo, ao próprio tipo de cidade que se poderia produzir, mais democrática e menos desigual. Neste sentido, passa a dialogar de forma mais estreita com o princípio de equidade, incentivando e orientando a participação de diversos atores sociais nos debates sobre planos e projetos, revelando assim seu caráter multidisciplinar. Isso, de certa forma, faz com que transcorrer hoje sobre mobilidade urbana seja transcorrer também sobre o significado da palavra cidadania, pois o tema evoca a responsabilidade que cada parcela da sociedade tem numa participação no mais alto grau da política que é o compromisso com o coletivo, contribuindo na busca de um melhor padrão de bem-estar social para todos.

A ideia e também a promoção da mobilidade urbana, sem desconsiderar a importância da eficiência no fator deslocamento, tenta centrar-se agora mais nas pessoas, compreendendo antes de tudo a construção de um sistema que oportunize e facilite aos cidadãos - hoje e no futuro - o acesso às oportunidades e às funções econômicas, culturais e sociais das cidades, possibilitando a todos a satisfação individual e coletiva de atingir os destinos desejados, necessidades, prazeres e realizações cotidianas. Envolve, por isso, e também eleva consideravelmente, de maneira mais sistemática e imbricada, o papel dos vários equipamentos do sistema de transporte e de suas relações com os outros sistemas e

\footnotetext{
3 A ideia de função social da cidade vem da atualização da Nova Carta de Atenas, realizada em 2003. Este documento estabelece não apenas quatro funções, como na Carta de 1933, mas dez funções, que são tratadas como conceitos. Referem-se sobretudo às cidades européias do futuro, mas são passíveis de adaptação e aplicação em qualquer cidade do mundo, já que as novas tecnologias e visão filosófica são divulgadas e adotadas com grande rapidez na atualidade. Os novos conceitos são: cidade para todos, cidade participativa, cidade saudável, cidade como refúgio, cidade produtiva, cidade inovadora, cidade ecológica, cidade cultural, cidade contínua e cidade acessível (GARCIAS \& BERNARDI, 2008).
} 
políticas urbanas. Isso exige uma ênfase maior no transporte coletivo do que no transporte privado, passando-se também a valorizar, no desenvolvimento urbano, as demandas de mobilidade peculiares dos usuários em geral e particularmente as necessidades dos usuários mais frágeis do sistema, como as crianças e jovens, pessoas com deficiência e os idosos. Ao mesmo tempo, essa ênfase maior no transporte coletivo caminha junto com uma orientação de inclusão social ${ }^{4}$, racionalidade de investimentos e redução de congestionamentos, fazendo da mobilidade urbana um elemento decisivo na conformação de algumas possibilidades de um desenvolvimento sócio-territorial mais equânime.

Acredita-se que para a implementação de uma política de mobilidade urbana voltada para fatores como cidadania, equidade e bem-estar, seja necessário que as políticas de transporte, circulação e acessibilidade estejam melhor articuladas com a implementação de políticas urbanas específicas, como a política ambiental, habitacional, de renovação e aproveitamento de áreas urbanas consolidadas, aproveitando ao máximo, e no que for possível, os equipamentos de interface ${ }^{5}$ do sistema de transporte público com o meio urbano, exigindo-se, assim, legislação específica para essas áreas.

\section{Mudanças recentes na legislação brasileira sobre mobilidade: oportunidade para uma melhor atuação dos transportes públicos na cidade}

Nos últimos anos vem surgindo no Brasil novas propostas e tendências no sentido de favorecer a equidade no espaço urbano com base no seu padrão de mobilidade e no sistema de transporte público, explícitas em alguns documentos e textos oficiais.

\footnotetext{
${ }^{4} \mathrm{~A}$ ideia de inclusão social refere-se aqui à um conjunto de meios e ações que combatem a exclusão aos benefícios da vida em sociedade, provocada, dentre outras, pela condição econômica, histórico social, localização, preconceitos sociais (gênero, etnia, deficiências, religião) e políticas deficitárias

${ }^{5}$ Equipamentos que proporcionam uma comunicação física e direta entre os sistemas de transporte e outros sistemas urbanos: estações metroferroviárias, terminais rodoviários e terminais multimodais.
} 
Tal perspectiva encontra amparo já no Estatuto da Cidade ${ }^{6}$, de 2001, cujas diretrizes exigem a melhoria da acessibilidade à equipamentos e atividades urbanas. A criação do Ministério das Cidades, em janeiro de 2003, veio com o objetivo de colocar em práticas as diretrizes do referido estatuto, com a elaboração de políticas públicas de desenvolvimento urbano, de habitação e de transporte urbano, visando combater as desigualdades sociais, transformando as cidades em espaços mais humanizados e ampliando o acesso da população aos serviços urbanos.

Mais recentemente, em 2012, foi criada a Política Nacional de Mobilidade Urbana7, buscando facilitar o acesso universal à cidade, o fomento e a concretização das condições que contribuam para a efetivação dos princípios, objetivos e diretrizes da política de desenvolvimento urbano, por meio do planejamento e da gestão democrática do Sistema Nacional de Mobilidade Urbana. Como um de seus princípios, tem-se o desenvolvimento sustentável das cidades, nas dimensões socioeconômicas e ambientais. Dentre seus objetivos destacam-se: I - reduzir as desigualdades e promover a inclusão social; e II promover o acesso aos serviços básicos e equipamentos sociais. Quanto às principais diretrizes estabelecidas pela Lei da Mobilidade Urbana, destacam-se: 1) integração com a política de desenvolvimento urbano e respectivas políticas setoriais; e 2) priorização de projetos de transporte público coletivo estruturadores do território e indutores do desenvolvimento urbano integrado.

Nesta perspectiva, Silva (2014) chama a atenção para o que ele considera como uma mudança de paradigma sobre a mobilidade urbana, presente na formulação da Lei da Política Nacional de Mobilidade Urbana, onde o termo "mobilidade urbana" vem substituindo em muitas abordagens o termo "transporte urbano". Segundo o autor, isto torna mais complexo e completo o olhar público sobre as formas de deslocamento e interação urbanos. Para Silva (op cit) há uma proposição, através de uma visão crítica, mas também integradora, na questão da mobilidade, de uma série de tópicos a serem levados em consideração na construção de políticas de mobilidade urbana, onde os meios de

\footnotetext{
${ }^{6}$ Lei no 10.257, de 10 de julho de 2001, que regulamenta o capítulo sobre Política Urbana da Constituição Federal Brasileira de 1988, criando diversos instrumentos que podem auxiliar na política de mobilidade urbana.

${ }^{7}$ Instituída pela Lei no 12.587 , de 3 de janeiro de 2012, é um instrumento da política de desenvolvimento urbano de que tratam o inciso XX do art. 21 e o art. 182 da Constituição Federal do Brasileira.
} 
transportes são levados em consideração como instrumentos que estejam integrados a uma vivência na cidade mais democrática, inclusiva, eficiente e igualitária. Silva (op. cit.) destaca ainda que entre os tópicos a serem considerados como parâmetros propostos para uma "nova" visão e análise da mobilidade urbana está o da inclusão social. Dessa forma, criou-se um ambiente institucional propício para o fomento da mobilidade através de projetos de infraestrutura urbana no Brasil.

Tem-se assim, talvez, a primeira oportunidade no Brasil de um tratamento mais efetivo dos equipamentos de interface e das complementaridades entre as políticas de transporte coletivo e as políticas de uso do solo. Sobre isto o próprio Ministério das Cidades diz:

\begin{abstract}
(...) este conceito tem como ponto de partida a percepção de que transporte não é um fim em si mesmo, mas uma forma da população acessar os destinos desejados na cidade. Desta forma, o sistema de mobilidade urbana pode ser considerado como um conjunto estruturado de modos, redes e infra-estruturas que garante o deslocamento das pessoas na cidade e que mantém fortes interações com as demais políticas urbanas. Considerando que a característica essencial de um sistema é a interação de suas partes e não as performances dos seus componentes tomadas em separado, um fator determinante na performance de todo o sistema é exatamente como as suas partes se encaixam, o que é diretamente relacionado com o nível de interação e compatibilidade entre agentes e processos intervenientes no sistema (MACÁRIO, 2003, apud Ministério das Cidades, 2005).
\end{abstract}

Apesar dos avanços que possa representar a recente Lei da Mobilidade Urbana, uma de suas fragilidades pode ser identificada na ausência de explicitação sobre o papel dos equipamentos de interface do sistema de transporte com o meio urbano e a utilização planejada dos seus espaços envolventes. Isto, contudo, não pode ser utilizado como argumento para o não tratamento dessa questão, considerando que a referida lei, além de estabelecer diretrizes, determina que todos os municípios com mais de 20 mil habitantes (cerca de $30 \%$ das cidades brasileiras), elaborem (sob pena de ficarem impedidos de receber recursos orçamentários federais destinados à mobilidade urbana, até que atendam tal exigência), um Plano de Mobilidade Urbana (PMU) ${ }^{8}$, capaz de abarcar não só as diretrizes da Lei, mas também de traçar, juntamente com a sociedade civil, um planejamento de curto, médio e longo prazos para a forma como se darão os deslocamentos de bens e sobretudo de pessoas na cidade. Esta ideia de fazer com que os municípios brasileiros realizem um

\footnotetext{
${ }^{8}$ O Plano de Mobilidade Urbana (PMU) é o instrumento de efetivação da Política Nacional de Mobilidade Urbana, e deverá contemplar os princípios, objetivos e diretrizes desta.
} 
planejamento ordenado do setor de transporte não é nova. Em 2001, o Estatuto das Cidades instituiu a obrigatoriedade do Plano Diretor, determinando que todas as cidades com mais de 500 mil habitantes elaborassem seu Plano de Transportes.

Além de uma diferença de denominação, à obrigatoriedade de elaboração do PMU soma-se a ampliação de seu universo de abrangência (mudança no termo de transporte para mobilidade), o que permite que a sociedade vislumbre outros aspectos ligados aos transportes coletivos, como por exemplo o fato de que estes devam contribuir para uma melhor equidade urbana.

A partir deste viés de maior abrangência, é que se vem pensando no tratamento mais planejado dos equipamentos de interface do sistema de transporte público, algo pouco expressivo e comumente ausente nos debates sobre os processos de transformação das cidades brasileiras, mas que precisa estar presente na elaboração dos PMU, sobretudo naqueles municípios dotados de uma malha metroferroviária estabelecida e em uso, como o Rio de Janeiro, que também vem recebendo novos investimentos com a implementação dos sistemas de BRT (Bus Rapid Transit), fomentando o debate e podendo colocar em prática políticas e ações que revertam essa tendência.

Fazendo parte dos PMU, com base nas diretrizes propostas pela Lei da Mobilidade Urbana, podem os equipamentos de interface serem entendidos como parte de um sistema estruturado e organizado que compreende os vários outros equipamentos de transporte e circulação e que pode manter fortes relações com outros sistemas e políticas urbanas. 0 PMU atuaria no sentido de promover a dinamização de alguns tecidos urbanos mais carentes, mas com tendência de reunir pessoas, atividades e serviços diversos, com a vantagem de poder interligá-los a outros pontos da cidade, na forma de espaços mais abertos e acessíveis por um meio de transporte coletivo, contrário a um modelo marcado por empreendimentos isolados e pouco acessíveis por transporte coletivo.

Faculta-se assim que a utilização controlada e o planejamento do espaço envolvente de alguns equipamentos de interface transporte $x$ meio urbano, integrando o PMU, ajude a melhorar a qualidade, distribuição e diversidade dos equipamentos e serviços implantados em algumas áreas urbanas, voltados à diversidade de grupos, culturas, etnias, faixa etária e níveis de renda. Além disso, fazendo parte de uma lei específica, ligada à mobilidade 
urbana, cuja sistemática de avaliação, revisão e atualização periódica não pode ser superior a 10 (dez) anos, possibilita que ações e projetos nesses espaços passem, caso necessário, por pequenas adaptações e mudanças, de acordo com a próprio ritmo da dinâmica urbana, retroalimentando de forma permanente novos processos e ações.

\section{Ações recentes de mobilidade urbana e transportes públicos na metrópole do Rio de Janeiro}

Nos últimos anos as discussões sobre as políticas de mobilidade e transporte público no Rio de Janeiro vêm ultrapassando cada vez mais a ideia de que estas devam estar centrada apenas na otimização do deslocamento físico, ainda que reconhecendo a importância deste, buscando também formas de (re)criar novas relações cotidianas entre pessoas e lugares, com uma melhor distribuição de serviços, equipamentos e atividades pela cidade. Sendo um dos maiores viabilizadores da mobilidade urbana, os equipamentos de transporte, considerados objetos sócio-técnicos, teriam, com esse pensameno, o objetivo de romper com a estanqueidade do território (KLEIMAN, 2015).

Nesse contexto, vêm pensando-se algumas ações e projetos urbanos voltados para antigas áreas da cidade que perderam total ou parcialmente suas funções de produção, entrando assim em estado de desuso e obsolescência. Esses espaços, considerados decadentes, revelaram-se, por uma razão ou outra, espaços potenciais para alguns tipos de investimentos, a fim de propiciarem uma certa renovação dessas áreas, ainda que sem um controle direto do poder público e uma participação efetiva da sociedade local.

Alguns fixos e fluxos passaram a buscar novas orientações na cidade, com a realocação de algumas concentrações e dispersões, buscando otimização e velocidade para a reprodução dos investimentos de médio e longo prazo, com algumas variações espaciais que incluem, dentre vários fatores, as inserções e/ou otimizações de estruturas de circulação e transporte coletivo, que acabam por valorizar e ressignificar alguns espaços. Desde a última década vêm surgindo novas tendências no sentido de favorecer a organização do espaço urbano do Rio com base no seu sistema de transporte público e empreendimentos a ele associados, 
princípio este já conhecido como Transit Oriented Development (TOD). Ainda que sem seguir integralmente o que propõe $O \operatorname{TOD}^{9}$, algumas ações têm reforçado as atenções na implantação ou revitalização de empreendimentos na área de influência do sistema de transporte público existente ou que se encontra em implantação, normalmente num raio até $1 / 4$ de milha (aproximadamente entre 400 e 500m) dos equipamentos de interface. No que concerne ao transporte público coletivo, dois importantes sistemas modais vêm participando de novas propostas e ações buscando uma melhor relação entre o transporte e a cidade: o metroferroviário e o recém implantando Sistema de Bus Rapid Transit (BRT), este último decorrente sobretudo da realização dos jogos olímpicos de 2016.

No sistema de transporte metroferroviário o local que muitas vezes vem sendo considerado ideal para as intervenções é o entorno dos seus equipamentos de interface, as estações metroferroviárias, as quais, inseridas no espaço geográfico, têm uma tendência natural de exercer um papel importante na relação do sistema de transporte com o ambiente urbano, podendo contribuir na implantação de projetos, uma vez que são focos de integração modal e canal de comunicação entre várias áreas urbanas. A concentração de atividades socioeconômicas no seu entorno, sobretudo as que estão mais ligadas ao consumo, tende a criar um tipo de uso do solo com características mais compactas. Esses aspectos têm feito com que algumas estações se tornem candidatas a pólos de articulação do transporte com o desenvolvimento socioeconômico e elemento importante na estruturação e organização do espaço urbano, contribuindo com ações afirmativas ${ }^{10}$ para a cidade.

Duas antigas áreas industriais, hoje servidas pelas estações de metrô Nova América/Del Castilho e Vicente de Carvalho (Fig. 1), zona norte da cidade, despontam a partir deste século como áreas especialmente atrativas para ações e projetos variados, com a emergência de novos conteúdos urbanos e usos do solo. Essas áreas vêm recebendo inúmeros investimentos, principalmente nos setores imobiliário e comercial, os quais se

\footnotetext{
${ }^{9}$ O TOD consiste basicamente em estratégias de planejamento e de ações relativas ao desenho urbano e de planejamento de transportes tratadas de forma integrada, realizadas por meio de políticas ou de instrumentos urbanísticos (NETO, 2011).

${ }^{10}$ Ações implementadas e coordenadas pelo poder público com o objetivo de amenizar desigualdades historicamente acumuladas, viabilizando novas e melhores oportunidades para camadas menos favorecidas da população.
} 
fazem sentir de forma mais incisiva no raio de $500 \mathrm{~m}$ da boca das estações, investimentos estes que continuam em alta ainda nos dias atuais (fig. 2, 3, 4 e 5).

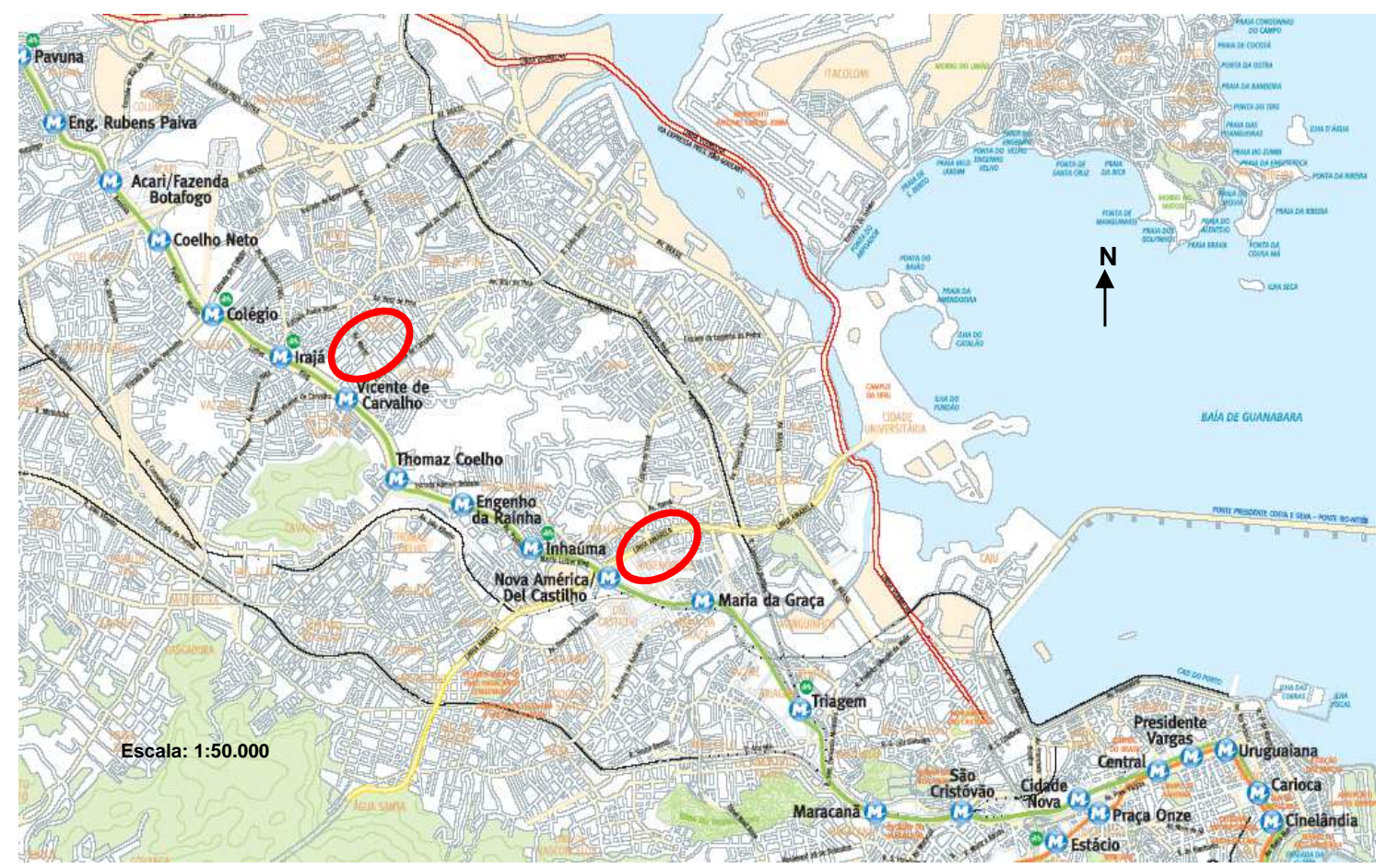

Fig. 1 - Mapa das estações Nova América/Del Castilho e Vicente de Carvalho (Fonte: Metrô- Rio, com marcações do autor).

Áreas com novos investimentos junto às estações

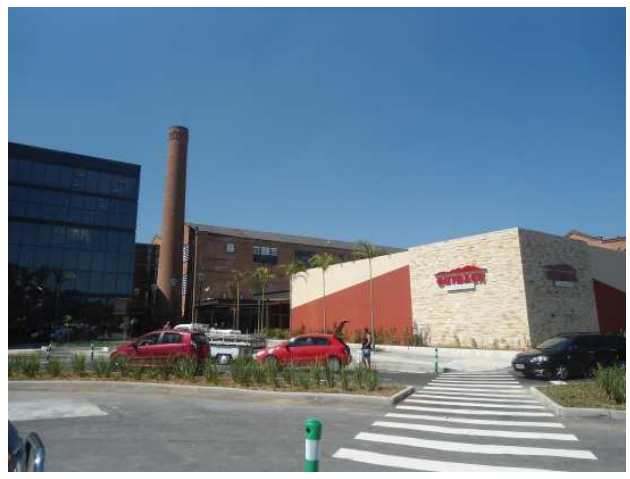

Fig. 2 - Novos serviços e atividades junto à estação Nova América/ Del Castilho Fonte: autor, 2013.

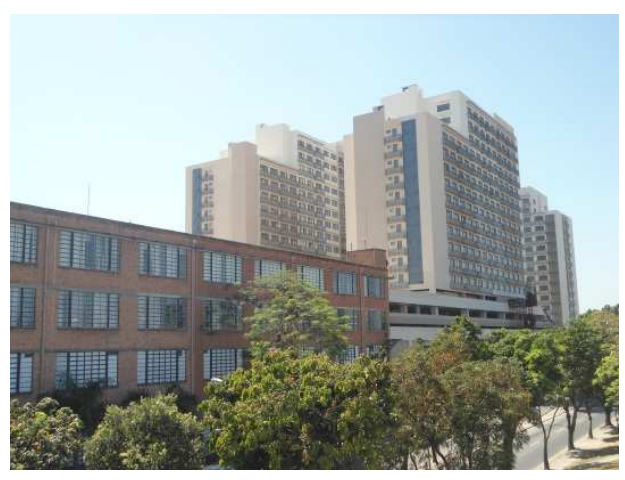

Fig. 3 - Torres comerciais junto à estação Nova América/Del Castilho Fonte: autor, 2013. 


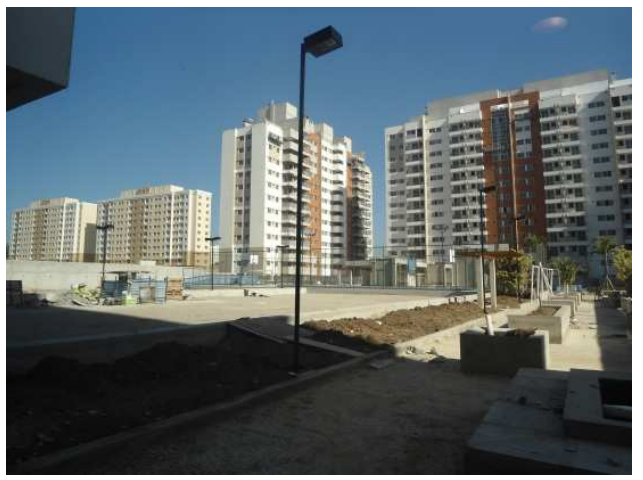

Fig. 4 - Prédios residencias junto a estação Vicente de Carvalho Fonte: autor, 2013.

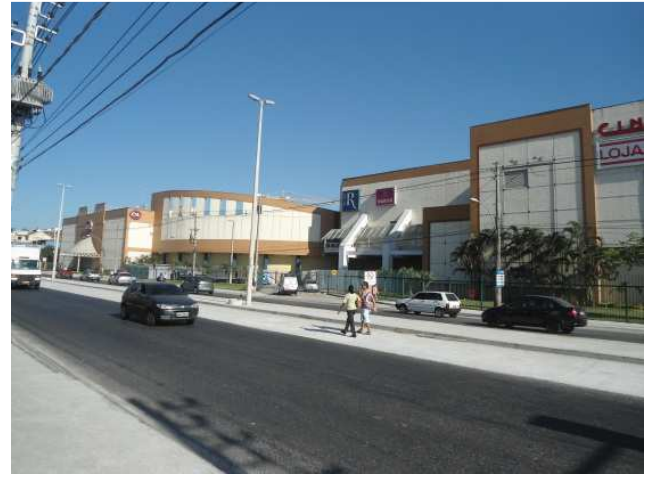

Fig. 5 - Serviços e Atividades junto à Estação Vicente de Carvalho Fonte: autor, 2013.

Esses investimentos têm trazido para áreas historicamente desfavorecidas, ainda que para faixas de rendas não muito abrangentes, um maior número de estabelecimentos e uma alteração do conjunto das atividades, serviços e do ambiente urbano, como: o aumento da possibilidade para mais pessoas acessarem bens e produtos (em especial no setor de comércio, educação, cultura e serviços); a renovação de espaços degradados (áreas antes desvalorizadas), com o estímulo ao desenvolvimento de pólos de prestação de serviços diversos no entorno das estações e pelos empreendimentos imobiliários lindeiros aos sistemas de transportes; e a valorização fundiária decorrente da relação direta entre a disponibilidade de infraestrutura e o desenvolvimento econômico. Acrescenta-se ainda o fato de que além de ser condicionante de opções locacionais, o aproveitamento racional e planejado do entorno desses equipamentos de interface pode constituir-se também em poderoso instrumento de redistribuição de renda e de melhoramento da qualidade de vida dos bairros e regiões mais pobres, com o aproveitamento de possíveis sinergias.

Diante desses fenômenos urbanos recentes no Rio de Janeiro, onde antigas áreas urbanas servidas por estações de metrô passaram e ainda passam por um processo de renovação e valorização, somado às tendências e propostas trazidas pela Lei da Política Nacional de Mobilidade Urbana, torna-se possível, e mesmo necessário, repensar a relação entre o transporte coletivo e cidade, com as estações participando na produção de um espaço urbano com mais equidade sócio-espacial.

Além de algumas ações e melhorias no sistema metroferroviário, o governo do Rio de Janeiro vem implantando nos últimos quatro anos um sistema com quatro linhas de BRTs: 
Transoeste, TransCarioca, TransOlímpica e TransBrasil (fig. 6 ), embora a previsão futura seja de um sistema com aproximadamente 10 linhas. O BRT é um sistema de transporte coletivo que utiliza ônibus articulados e os faz circular em faixas ou vias exclusivas, com o objetivo de promover um serviço rápido, eficaz, confortável e a custos moderados. Basicamente, um sistema de BRT busca incorporar as melhores características de desempenho de modernos sistemas ferroviários, conciliando-as com a flexibilidade do sistema de veículos de transporte coletivo rodoviário. Desta forma, torna-se um sistema integrado designado para melhorar a velocidade, confiabilidade e identidade do sistema convencional de ônibus, mas com custos acessíveis à grande maioria das cidades, uma vez que sua implementação é considerada mais barata e mais rápida quando comparada a outros investimentos em transportes coletivos, sobretudo aos sistemas que operam sobre trilhos.

Espera-se, segundo o poder público local, que a implantação dessas linhas de BRTs no Rio de Janeiro tragam uma melhoria da mobilidade, buscando uma maior integração entre esse modal e os demais modais de alta capacidade (trem e metrô). De acordo com a Secretaria Municipal de Transporte, a implantação dessa rede de BRTs, considerada como uma "nova modalidade" de transporte coletivo urbano na cidade, tem entre seus principais objetivos a redistribuição modal no transporte público, buscando elevar para mais de $50 \%$ o percentual de usuários não impactados pelo trânsito (passageiros de metrô, trem e BRT) nos próximos dois anos.

Paralelo a esse processo, observa-se que as diretrizes do TOD, antes aplicadas principalmente no entorno de estações metroferroviárias, vêm, em alguns casos, sendo pensadas também no entorno de grandes terminais rodoviários, como o sistema de BRT, e também de terminais multimodais. Isso tem incentivado, a partir de algumas relações com os princípios de equidade urbana, alguns estudos voltados para se pensar os sistemas de BRT do Rio e sua participação num planejamento urbano mais equânime, visando uma cidade mais coesa, considerando que esses sistemas de transporte cortam grandes áreas consolidadas e densas da cidade, historicamente carentes de vários serviços e equipamentos urbanos.

Estudo desenvolvido atualmente em parceria com o Laboratório Redes Urbanas, do Instituto de Pesquisa e Planejamento Urbano e Regional da Universidade Federal do Rio de 
Janeiro (IPPUR/UFRJ), voltado para a linha de BRT da TransBrasil (fig. 6), prevista para entrar em funcionamento em 2017, vem discutindo e apontando alguns caminhos iniciais para se pensar um método de planejamento envolvendo o aproveitamento racional e sistemático da envolvente de seus terminais rodoviários e multimodal, passível de ser replicável, talvez, para outros corredores de transporte de massa na cidade, conforme apontamento do Instituto de Políticas de Transporte e Desenvolvimento (ITDP - Brasil)

O BRT TransBrasil, segundo o ITDP, tem o potencial de se tornar um dos corredores de BRT de maior capacidade do mundo. O corredor pode redefinir o uso e a ocupação da Avenida Brasil (fig. 6), uma das vias expressas mais emblemáticas da cidade do Rio, que hoje constitui uma cicatriz cortando bairros degradados na região suburbana da cidade. $O$ corredor da Transbrasil oferece uma ótima oportunidade para reestruturação urbana destes bairros, a começar pelo entorno das estações e terminais, fazendo com que deixem de ser espaços somente de passagem, e se tornem espaços de trabalho, vivência, estudo, cultura e lazer. O estudo inicialmente, diante do grande tamanho e características da área que será cortada pela TransBrasil, e sem desconsiderar outras possibilidades, vem concentrando-se em três pontos específicos, delimitados por três futuros importantes terminais da linha, sendo dois rodoviários e um multimodal: Terminal Multimodal de Deodoro, Terminal das Margaridas e Terminal das Missões (fig. 6). Tenta-se com isso identificar as características físicas, sociais, culturais e econômicas existentes em cada área, no sentido de pensar o desenvolvimento de cada uma orientado ao transporte coletivo. Com isto tenta-se também pensar uma definição conceitual para o significado da linha TransBrasil para a cidade como um todo. 


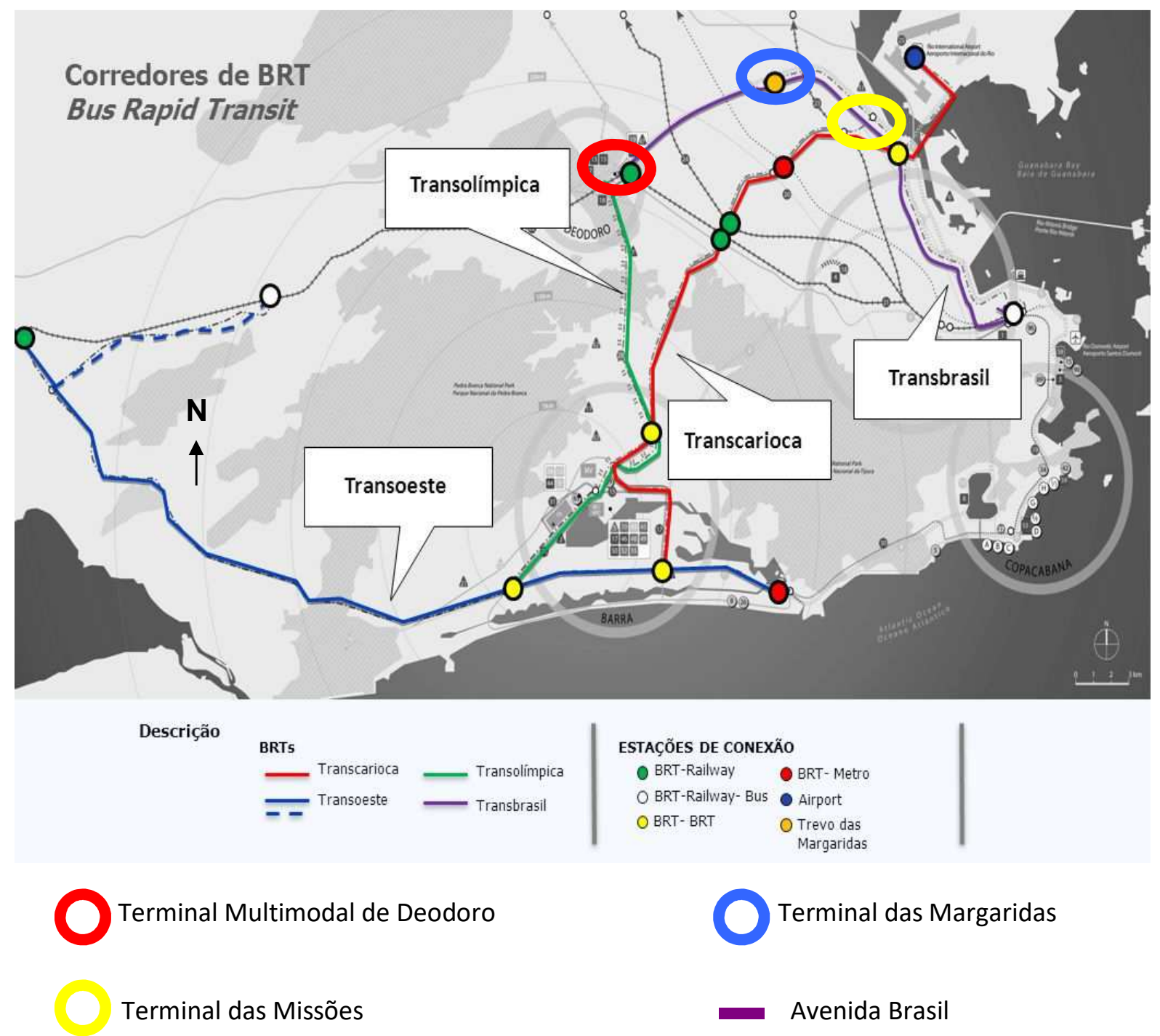

Fig. 6 - Linhas de BRT do Rio de Janeiro e futuros terminais da TransBrasil

Pensa-se inicialmente que as áreas envolventes desses pontos de interface ao longo da TransBrasil, através de um plano específico e uma intervenção controlada, sejam capazes de oferecer condições para uma melhor interatividade de ações e atores, pela conexão de densidades de pessoas, atividades, equipamentos e práticas sediadas nessas áreas de nodalidades urbanas, criando-se possibilidades de enfrentamento dos desafios referentes aos quadros de desigualdade sócio-espacial e fraca coesão de alguns contextos urbanos. 


\section{Um plano de mobilidade urbana para o Rio de Janeiro e a inserção dos equipamentos de interface como possíveis meios de desenvolvimento urbano}

No Rio de Janeiro, embora alguns processos recentes já sinalizem possíveis mudanças de pensamento, não há um aproveitamento e um uso planejado do entorno dos equipamentos de interface do sistema de transporte público coletivo, deixando transparecer um certo "atraso" em relação à outras metrópoles nacionais e estrangeiras, como Curitiba, São Paulo, Brasília, Cleveland, Madrid, Toronto e Lisboa. Ainda que em algumas dessas também inexista legislação específica para o aproveitamento do espaço envolvente dos equipamentos de interface, já há sinais de significativos avanços, com alguns instrumentos incentivando a participação e envolvimento de vários atores urbanos, relativizando assim a predominância do interesse do capital privado.

No Rio o sistema metroferroviário regulamentado opera sem um planejado e efetivo aproveitamento do entorno de seus equipamentos de interface, a notar-se pelo estado de sub-utilização e degradação presente em vários pontos da linha dois do metropolitano e de alguns ramais ferroviários. Esta situação, acredita-se, é reflexo da falta de investimentos e modernização dos sistemas de alta capacidade, especialmente ao longo das últimas três décadas, e da ausência de uma política orientada para a complementaridade entre os sistemas de alta capacidade e o ambiente construído.

O Sistema de BRT, à exceção de algumas discussões acadêmicas, vem sendo projetado e implantado sem um planejamento específico do uso do solo ao longo do seu trajeto (estações) e nas áreas envolventes de seus terminais, desconsiderando aspectos urbanísticos e sócio-econômicos das áreas ao longo do trajeto, caracterizando-se mais como um tipo de canalização do movimento pendular ${ }^{11}$, provocando um efeito "túnel" em seu percurso: os veículos passam, mas de forma "cega", sem compreender por onde passam (KLEIMAN, PACHECO, EYER, 2016).

\footnotetext{
${ }^{11}$ Movimento realizado diariamente no sentido casa-trabalho-casa, entre os bairros e municípios de uma região metropolitana.
} 
Um dos principais desafios que se coloca atualmente para a gestão pública no Rio de Janeiro, prende-se não apenas à otimização dos equipamentos e operação do sistema de transporte público, mas também à capacidade de relacioná-los com as propostas da Política Nacional de Mobilidade Urbana, através, por exemplo, da realização de projetos e programas de renovação urbana que englobe o aproveitamento planejado do entorno dos equipamentos de interface.

Tal perspectiva pode vir a ganhar efetividade com o Plano de Mobilidade Urbana Sustentável do Rio de Janeiro (PMUS-Rio), atualmente em desenvolvimento pela Secretaria Municipal de Transporte, com propostas de estudo para os cenários até o ano de 2026, tentando fazer com que a cidade do Rio de Janeiro se enquadre nas diretrizes da Política Nacional de Mobilidade Urbana (Lei 12.587/2012). O PMUS-Rio inclui o desenvolvimento de cenários de investimentos em infraestrutura de transporte e cenários de desenvolvimento de uso do solo e propostas de melhoria dos programas públicos de mobilidade. Dentre os seus principais objetivos está o de definir ações estratégicas para priorizar o transporte público e o desenvolvimento de cidades mais equânimes e equilibradas no território. Isso significa abordar a mobilidade de forma estratégica para a cidade, não tratando apenas de problemas específicos, pontuais ou restritos.

Mesmo sendo um plano municipal, o PMUS-Rio leva em conta demandas e aspectos metropolitanos, considerando inclusive o Plano Diretor de Transporte Urbano da Região Metropolitana do Rio de Janeiro (PDTU - 2013). Assim, a cidade do Rio de Janeiro deve ser encarada como o foco do Plano e a Região Metropolitana como a área de influência do mesmo. A partir disto, e considerando também o fato de que um dos principais aspectos do PMUS-RIO seja a integração dos projetos de transporte público coletivo com a política mais ampla de desenvolvimento urbano, pode o referido plano prevê a delimitação de áreas de influência no entorno dos equipamentos de interface do sistema metroferroviário e do sistema de BRT, normalmente de 400 a $500 \mathrm{~m}$ de raio a partir desses equipamentos, passando a sererm consideradas assim como Áreas de Intervenção Especial e Controlada (AIEC).

Com diretrizes e normas específicas voltadas para o aproveitamento controlado das AIEC, além de um caráter multidisciplinar na sua elaboração, contando para isso com a 
participação de diversas secretarias municipais, o PMUS-Rio pode vir a ser uma ferramenta de auxílio ao poder público, em parceria com o poder privado e a sociedade civil, no desenvolvimento não apenas de ações votadas para a infra-estrutura viária e sistema de transportes coletivos, mas também na elaboração e coordenação das ações e projetos urbanos realizados nas áreas de influência dos equipamentos de interface, promovendo uma articulação mais estreita e concertada entre os setores de transporte coletivo e o urbanismo, favorecendo o desenvolvimento econômico, amenizando desigualdades sócioespaciais e possibilitando a disseminação de serviços, atividades e equipamentos urbanos por áreas já consolidadas e menos privilegiadas.

Tendo em vista que o PMUS-Rio vem trabalhando com um horizonte de 11 anos, a partir de 2015, recomenda-se que no decurso desses anos seja feito um trabalho inicial de levantamento, identificação e aproveitamento planejado do entorno de alguns equipamentos de interface do sistema metroferroviário e do sistema de BRT, a fim de que esses espaços possam receber, de forma planejada, incentivos para novos empreendimentos, atividades e serviços diversos. As ações e projetos precisariam ser analisados caso a caso, principalmente quanto às repercussões na produção futura de um quadro urbano que viabilize uma maior equidade na distribuição de oportunidades, serviços e equipamentos urbanos.

A indicação dos equipamentos de interface mais propícios aos empreendimentos e projetos não é uma coisa simples, exigindo-se o levantamento e análise minuciosa de importantes aspectos da área como: 1) população, empregos, renda; 2) faixa populacional excluída dos transportes coletivos por questões tarifárias; 3) Identificação da rede de transporte coletivo que atende à área e da demanda transportada nestas linhas; 4) Identificação das áreas com mais potencial de urbanização e/ou menos propícias ao adensamento, em relação à capacidade dos corredores de transporte; 5) Identificação da dependência da população da área pelo transporte coletivo; 6) evolução do uso do solo e adensamento populacional com a evolução da oferta de serviços de transporte; 7) Caracterização do sistema viário local; e 8) Identificação da localização dos equipamentos de interface e sua possível interferência no entorno. Reconhece-se que esses aspectos são apenas iniciais, podendo surgirem outros no decorrer dos processos de levantamento. 
Intervir de forma planejada em algumas áreas, a partir de uma política que busque identificar os equipamentos de interface com maior potencialidade para desenvolvimento urbano, no caso o PMUS-Rio, pode ter um duplo efeito que ajude na construção de um melhor quadro de equidade social: 1) ajudar a encontrar soluções que potencializem e diversifiquem as atividades e serviços locais, trazendo inúmeros benefícios não só para a população mais próxima dos pontos e equipamentos de interface, mas também das áreas e municípios adjacentes, facilmente acessíveis pelo transporte coletivo, desenvolvendo uma melhor vivência e apropriação do espaço público, contribuindo ainda para renovar a imagem dessas localidades frente à cidade, ajudando a quebrar alguns preconceitos sociais existentes; e 2) promover um tipo de continuidade entre essas áreas e outros espaços metropolitanos adjacentes.

Pretende-se que o produto final do plano, mais que uma obrigação legal, seja uma contribuição importante na tarefa da universalização do direito à mobilidade urbana e na construção de uma cidade mais equânime e sustentável.

\section{Considerações finais}

O Rio de Janeiro vem enfrentando nos últimos anos algumas de suas demandas na mobilidade urbana com fortes investimentos no setor de transportes. É o caso dos BRTs e da ampliação e modernização do sistema metroferroviário. São intervenções necessárias e importantes.

Mas numa região (capital e municípios do entorno metropolitano) onde o sistema de transporte tem grandes e crônicos contenciosos, em razão da inexistência de uma sólida política para o setor de mobilidade urbana, é preocupante constatar que o planejamento e os investimentos nos espaços envolventes dos equipamentos de interface, bem como os investimentos no próprio sistema de trilhos (metrô e trem), não acompanham as carências da região. Tal fato deve-se principalmente à uma não integração de seus equipamentos de interface à um programa urbano mais amplo, que aborde a realidade presente e as 
projeções para o futuro de grandes áreas da cidade, sobretudo as mais carentes, que teriam boas oportunidades de desenvolvimento e nova qualidade em serviços e atividades.

O chamado subúrbio do Rio de Janeiro, onde está a quase totalidade das estações ferroviárias, além de inúmeras estações metroviárias, e agora também as novas linhas de BRT, é uma imensa área urbana, considerada a mais central e populosa da metrópole. Precisa de políticas que articulem os equipamentos de interface dos sistemas de transporte coletivo com as propostas de desenvolvimento urbano. É preciso estimular o uso de grandes áreas pouco aproveitadas ou vazias, bem localizadas que são no contexto da metrópole, fomentando um ambiente promissor se for visto como novos olhos e sem ser tachado de decadente ou sem futuro.

Com a implantação do sistema de BRT, ainda que não seja este considerado como o mais adequado para ser a espinha dorsal do transporte público no Rio de Janeiro, considerando sua elevada densidade demográfica, é preciso tirar o melhor proveito de cada contexto, reconhecendo suas peculiaridades e potencialidades. É necessário que concomitantemente ao BRT, o entorno dos equipamentos de interface e as condições de cada local façam parte de um projeto permanente que busque melhorar a vida de faixas menos privilegiadas da população, disponibilizando novas atividades e equipamentos, visando um melhor quadro de equidade urbana, de maneira mais democrática e coletiva, algo ausente nas ações do poder público no Rio de Janeiro, mais já sinalizado pela Lei da Política Nacional de Mobilidade Urbana. Mais do que transformações físicas, a construção do sistema de BRT, ressalvada as questões de ordem operacional que possa envolver, deve permitir que um grande número de pessoas possam usufruir de novas situações, serviços e lugares, contribuindo na formação de uma consciência social e política acerca da importância dos projetos e ações planejadas no entorno dos equipamentos de interface.

Conquanto não seja o único caminho possível para auxiliar no desenvolvimento de um pretenso quadro de melhor equidade urbana, dependendo inclusive de outras ações para sua eficácia, vale a pena considerar, e as experiências confirmam, as ações e projetos planejados no entorno dos equipamentos de interface do sistema de transportes coletivos, como uma alternativa visando a valorização e dinamização de muitas áreas da cidade, sendo um instrumento fundamental e de imenso potencial, merecedor de tratamento e atenção 
especial numa política, como o Plano de Mobilidade Urbana Sustentável, que aborde de forma inovada e unificada a questãos do transporte coletivo e da mobilidade no Rio de Janeiro.

Muito além de uma reordenação das formas e deslocamentos, está em jogo neste momento o próprio futuro da metrópole do Rio de Janeiro, futuro este que para ser melhor não pode prescindir da ideia de mobilidade em um novo paradigma, abordando a relação dos deslocamentos das pessoas com o planejamento das cidades para um desenvolvimento mais harmônico e justo, de modo a propiciar o acesso universal da população às oportunidades oferecidas pela cidade.

\section{Referências bibliográficas}

ABREU, Maurício. Políticas Públicas, Estrutura Urbana e Distribuição da População de Baixa Renda na Área Metropolitana do Rio de Janeiro. Rio de Janeiro: IDCR/CNPU, IBAM, 1978.

BALASSIANO, Ronaldo; ALEXANDRE, Richard William Campos. BRT no Rio de Janeiro: Implicações para Mobilidade Urbana. Programa de Engenharia de Transportes - PET/COPPE/UFRJ. In: X Rio de Transportes. Rio de Janeiro, ago/2012.

BRANCO, Soraia Patrícia Videira Martins. Estudo e Aplicações de Sistemas BRT - BUS RAPID TRANSIT. Dissertação (Mestrado em Engenharia Civil - Especialização em vias de comunicação). Universidade do Porto, 2013.

CABRAL, Richele; TEIXEIRA, Eunice Horácio S. B.; BORGES, Milena S.; et al. BRT Transoeste: transformando o conceito de transporte público no Rio de Janeiro. Fetranspor - Federação das Empresas de Transportes de Passageiros do Estado do Rio de Janeiro.

CAMPBELL, T . Justice. Basingstoke: Macmillan, 1988.

DAVEY, K ; DEVAS, N. Urban Government Finance. In Davey, K (ed.) Urban Management, the Challenge of Growth. Avebury: Aldershot, 1996.

DUARTE, Ronaldo Goulart. O processo de reabilitação e renovação urbana na cidade do Rio de Janeiro e suas perspectivas. In: Scripta Nova. Revista electrónica de geografía y ciencias sociales. Barcelona: Universidad de Barcelona, vol. IX, no 194 (44), 2005.

FAINSTEIN, S. The just city. Ithaca, NY: Cornell University Press, 2010.

FIREMAN, Theny Mari. Como e por que as desigualdades sociais fazem mal à saúde de Rita Barradas Barata. Maceió - Brasil, 2014. Disponível em http://www.redehumanizasus.net/83835-leitura-do-texto-3. Acessado em 06jul2016.

GARCIAS, Carlos Mello; BERNARDI, Jorge Luiz. As funções sociais da cidade. In: Revista Direitos Fundamentais e Democracia. vol. 4, 2008.

GRAVE, Leila Marcia Neri. ANTP- Curso de Gestão da Mobilidade Urbana. Ensaio Crítico - Turma 12 o conceito de equidade na mobilidade urbana e a realidade da cidade de Salvador. S.d. 
INSTITUTE FOR TRANSPORTATION AND DEVELOPMENT POLICY - ITDP. The path to sustainable urban development. Londres/Rio de Janeiro, 2016.

KLEIMAN. Mauro. Transportes e mobilidade e seu contexto na América Latina. Série Estudos e Debates (IPPURUFRJ), $n^{\circ} 61$, p. 1-10. 2011.

KLEIMAN. Mauro.Transportes e Cidadania - a problemática dos transportes e a questão da mobilidade urbana das camadas de baixa renda como necessidade e direito social na metrópole do Rio de Janeiro. Instituto de Pesquisa e Planejamento Urbano e Regional/Universidade Federal do Rio de Janeiro (IPPUR-UFRJ). Rio de Janeiro, RJ, 2015.

KLEIMAN. Mauro; PACHECO, Alana Silva; EYER, Tassiane Gavina. Traçado versus trama urbana no BRT Transcarioca: qual a relação compreendida entre o percurso e os lugares do trajeto? In: Revista Chão Urbano, 2016.

KOWARIK, Lucio. A Espoliação urbana. São Paulo: Paz e Terra, 1970.

LIMA, José Júlio Ferreira. O conceito de eqüidade social como referencial para avaliação de políticas urbanas. In: III CONGRESSO BRASILEIRO DE DIREITO URBANISTICO - Balanço das experiências de implementação do Estatuto da Cidade. Recife - Brasil, 2004.

MINISTÉRIO DAS CIDADES - BRASIL. Mobilidade e política urbana: subsídios para uma gestão integrada. Coordenação de Lia Bergman e Nidia Inês Albesa de Rabi. - Rio de Janeiro: IBAM; Ministério das Cidades, 2005.

NETO, Vicente Correia Lima. Desenvolvimento Orientado ao Transporte: o potencial de aplicação pela Companhia Brasileira de Trens Urbanos. IPEA, Boletim Regional, Urbano e Ambiental, no 5, junho de 2011.

PREFEITURA DA CIDADE DO RIO DE JANEIRO. Plano de Mobilidade Urbana Sustentável da Cidade do Rio de Janeiro (PMUS-RIO). Disponível em: http://www.rio.rj.gov.br/web/pmus/sobre. Acesso em 15jul2016.

SILVA, Vinícius Fernandes da. Uma análise sobre a mobilidade urbana na Baixada Fluminense como contribuição na formulação de uma sociologia dos transportes no Brasil - Em pé ou sentado?. 2014. 260 f. Tese (Doutorado em Planejamento Urbano e Regional) - Instituto de Pesquisa e Planejamento Urbano e Regional, Universidade Federal do Rio de Janeiro, Rio de Janeiro, 2014.

VASCONCELLOS, Eduardo Alcântara. Transporte Urbano, Espaço e Eqüidade: análise das políticas públicas. 3ạed. São Paulo: Annablume, 2001.

VETTER, D; MASSENA, R. Quem se Apropria dos Benefícios Líquidos dos Investimentos do Estado em Infraestrutura Urbana? Uma Teoria de Causação Circular. In Silva, L (ed.) Solo Urbano, Tópicos sobre o Uso da Terra. Rio de Janeiro: Zahar, 1982. p. 49-77. 